\title{
Manav Rakshak: Device to Help Maintain Social Distancing
}

\author{
Abhiruchi Passi, Devdutt
}

\begin{abstract}
Abstract: On March 11, 2020, the World Health Organization (WHO) confirmed COVID-19 a pandemic, in response to the more than 1,00,000 confirmed cases globally in more than 100 countries, and the persistent threat of spreading further. Presently, there is no medicine to cure or vaccine to prevent the spread of COVID 19. The only way to curb its menace is taking precautionary measures as advised by Health experts. Social distancing i.e. maintaining a minimum distance of 1-1.5 meter between two individuals is one of the proactive measures advised by WHO. In this paper, an ATMEGA (open source) based Smart wearable device "Manav Rakshak" is proposed. It can be worn while travelling outside home and will help in maintaining the social distancing thereby curb the spread of COVID-19.

Keywords : COVID 19, pandemic, Social Distancing, WHO
\end{abstract}

\section{INTRODUCTION}

A coronavirus is a type of common virus that infects our upper respiratory tract system including throat and nose. It derives its name from its crown like shape when observed under a microscope. As per World Health Organization (WHO), a pneumonia of unknown cause detected in Wuhan, China was first reported to the WHO Country Office in China on $31^{\text {st }}$ December 2019. The outbreak was declared a Public Health Emergency of International Concern on $30^{\text {th }}$ January 2020. On $11^{\text {th }}$ February 2020, WHO announced a name for the new coronavirus disease: COVID-19. The situation was monitored closely along with daily assessment of the number of confirmed cases of COVID-19 across the globe. On March 11,2020 , as per WHO report, in the past two weeks, the number of cases of COVID-19 outside China had increased 13-fold, and the number of affected countries tripled. With more than 1,18,000 cases in 114 countries, and 4,291 people having lost their lives, COVID-19 was spreading alarmingly. In the ensuing days and weeks ahead, it was feared that the number of cases, the number of deaths, and the number of affected countries would increase further. Consequently, WHO characterized COVID-19 as a pandemic [1]. It spreads through the novel Corona Virus. The microscopic image of Coronavirus is shown in Figure 1.

Revised Manuscript Received on April 27, 2020.

* Correspondence Author

Abhiruchi Passi*, Electrical, Electronics and Communication Engineering Department, Manav Rachna International Institute of Research and Studies, Faridabad, India. Email: abhiruchi.fet@mriu.edu.in

Devdutt, Electronics and Communication Engineering Department, Manav Rachna International Institute of Research and Studies, Faridabad, India.. Email: devduttsharma0249@gmail.com

(C) The Authors. Published by Blue Eyes Intelligence Engineering and Sciences Publication (BEIESP). This is an open access article under the CC BY-NC-ND license (http://creativecommons.org/licenses/by-nc-nd/4.0/)

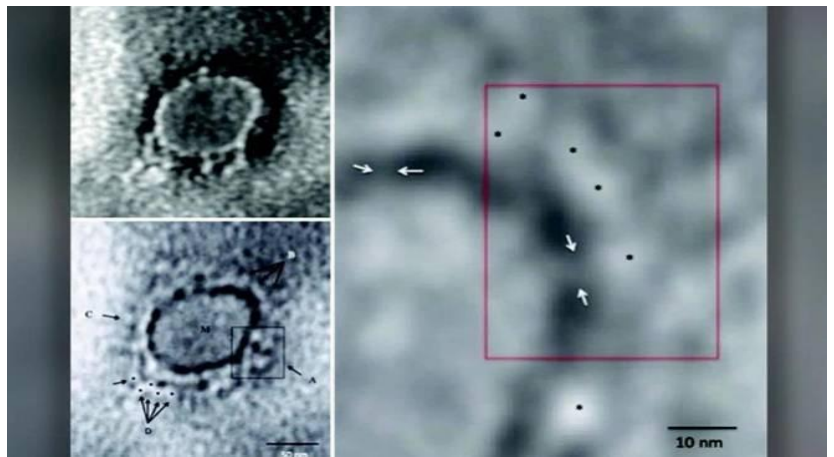

Figure 1: Microscopic Image of Corona Virus (Source:

Indian Journal of Medical Research (IJMR)) [2]

The number of people infected with this deadly disease is increasing in India also. In line with the directions and guidance of the World Health Organization, the Government of India, has taken active steps with an aim to curb the spread of this disease. As per advisory issued the suspected patient should look for the following signs and symptoms:

- Fever

- Cough

- Shortness of breath or difficulty in breathing

Presently there is no medicine to cure or vaccine to prevent COVID-19. As they say prevention is better than cure, is aptly suitable in the current scenario. The best way to prevent infection is to avoid being exposed to the virus through the following measures:

I. Observe good personal Hygiene

II. Practice frequent hand washing with soap

III. Covering mouth when coughing and sneezing

IV. Social Distancing

As per Health Experts Social Distancing can be an effective measure to curtail the spread of COVID-19. Social distancing is purposely maintaining the physical space between individuals to prevent spread of illness. Keeping a distance of at least one metre from other people lessens the chances of getting infected with COVID-19.

Social distancing is a non-pharmaceutical infection prevention and control intervention implemented to avoid/decrease contact between those who are infected with a disease causing pathogen and those who are not, so as to stop or slow down the rate and extent of disease transmission in a community. This eventually leads to decrease in spread, morbidity and mortality due to the disease. In addition to the proposed interventions, the State/UT Governments may prescribe such other measures as they consider necessary [3]. For effective impact of social distancing the authorities have also taken the following measures:

Published By:

Blue Eyes Intelligence Engineering \& Sciences Publication

(C) Copyright: All rights reserved. 
- Work from home

- Closing of Educational Institutions and Coaching centres and shifting to online mode

- Keeping in touch with near and dear ones using audio and video calls

- Annulling or deferring meetings, seminars and conferences.

There may be instances where movement or travelling of people is necessary to provide essential services like food, medicine, hospitals, banks etc. Social distancing in such scenario can be observed in the following manner:

- Keeping a distance of at least 1-1.5 metre between individuals

- Greet people with Namaste instead of handshakes

- Usage of electronic money instead of currency

- Avoid public transport

- Maintaining a distance of at least 1-1.5 metre while standing in a queue for shopping

The individuals who are staying at home should take the following precautions:

- Wash hands frequently with soap

- Request visitors to avoid coming home

- Avoid visiting markets and shops for buying essentials and prefer the home delivery option

- Frequently sanitize surfaces like door knobs, taps, kitchen surfaces and other objects that are touched on a regular basis

Technology can be effectively used for maintaining the requisite distance as per social distancing norms. The proposed system uses a wearable device capable of sensing the distance between two individuals and triggering an alarm in the event of proximity between the individuals.

\section{PROPOSED SYSTEM}

The wearable device consists of Ultrasonic Sensor, Buzzer and a microcontroller. The Sensor will detect the distance between the wearer and other individual. The microcontroller is programmed to verify the desired distance and trigger the alarm accordingly. The block diagram of the proposed system is shown in Figure 2.

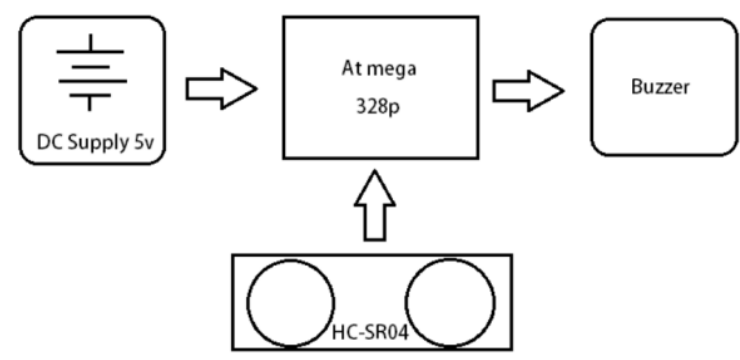

Figure 2: Block Diagram of the proposed System

The hardware components used are :

(i) Battery (5v) - It supplies requisite power for operationalisation of the entire circuitry.

(ii) ATMEGA 328P microcontroller - It is a high performance, low power controller from Microchip. ATMEGA328P is an 8-bit microcontroller based on AVR RISC architecture. The Atmega328 has 28 pins. It has 14 digital I/O pins, of which 6 can be used as PWM outputs and 6 analog input (I/O) pins. These I/O pins account for 20 (GPIO) general purpose input output of the pins [4].

(iii) Buzzer - A buzzer is a tiny component to provide sound features to the system. It is a compact 2-pin polarized structure; hence can be easily used in various structures.

(iv) HC-SR04 - The HC-SR04 Ultrasonic (US) sensor consists of 4 pins viz. Vcc, Trigger, Echo and Ground. This sensor is a widely used sensor in several circuits where measuring distance or sensing objects is required. The Sensor's operating frequency is $40 \mathrm{~Hz}$ and operating current is less than $15 \mathrm{~mA}$. The component has a transmitter, which transmits an ultrasonic wave. This wave propagates in air and on being objected by any material, it gets reflected back towards the sensor and is received by the receiver [5].

The circuit Diagram of the proposed system is shown in Figure 3.

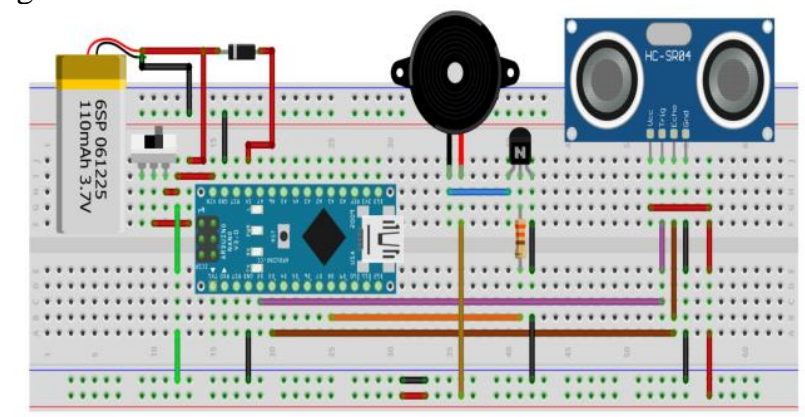

Figure 3: Circuit Diagram of the proposed System

\section{WORKING OF THE PROPOSED SYSTEM}

During quarantine we need to maintain social distancing of at least 1-1.5 meter from the people and in public places. But sometimes human brain does not remember the precaution of maintaining social distancing. So, we have come up with a smart solution called Manav Rakshak. It is a smart wearable device which can be used for maintaining social distancing from people. It contains an ultrasonic sensor, microcontroller and a buzzer. HC-SR04 ultrasonic sensor (US) is used for measuring distance from body to object. And this measured signal by ultrasonic sensor is sent to the microcontroller. The program/ code is already uploaded in the microcontroller. The condition implemented in the code is that when the distance is greater than 1.5 meter the condition goes true and the electric buzzer starts blowing. And on other side if the distance is less than 1.5meter the other condition goes true and electric buzzer will not blow this time.

The prototype Model is shown in Figure $4 \mathrm{~A}$ and B:

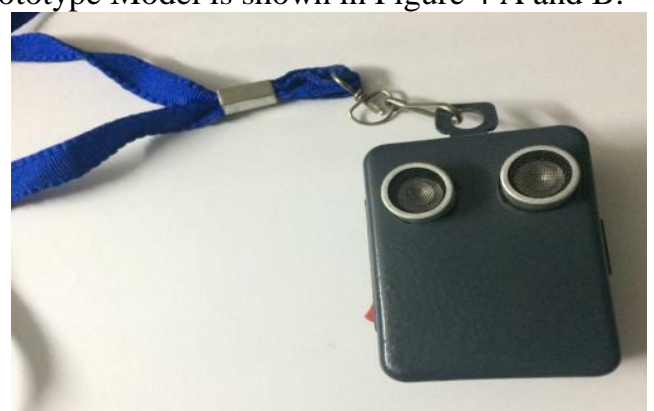

Figure 4 A: Prototype Model

Published By:

Blue Eyes Intelligence Engineering \& Sciences Publication

(C) Copyright: All rights reserved.
DOI: 10.35940/ijeat.D7914.049420

Journal Website: www.ijeat.org 


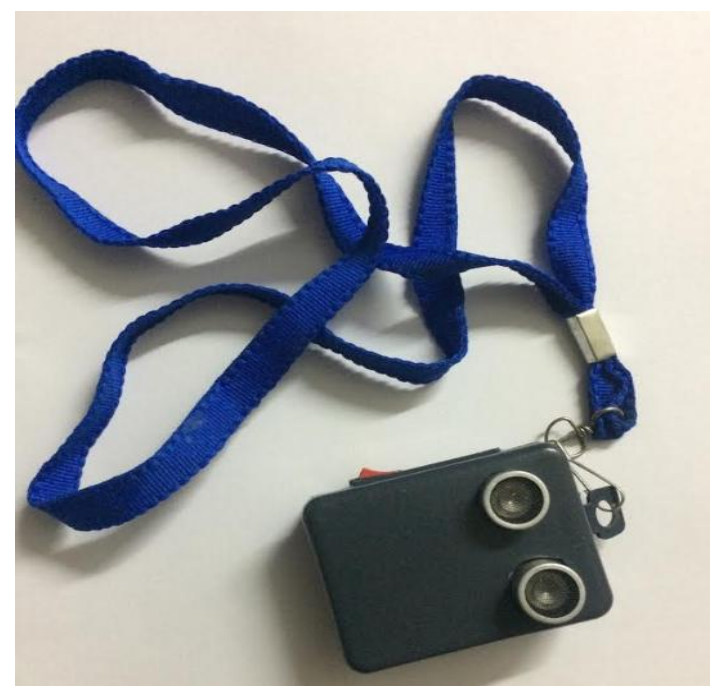

Figure 4 B: Prototype Model

\section{SERIAL MONITORING}

The conditions implemented in the program are as follows:

1 - If the object/ wearer is at a distance of less than $1.5 \mathrm{~m}$ from sensor the buzzer will start blowing till the sensor range is not greater than equal to $1.5 \mathrm{~m}$.

2- The other condition is that if the sensor is at a distance greater than $1.5 \mathrm{~m}$ then this is safe distance as per the program and so the buzzer will not blow.

Serial monitoring of the proposed system is shown in Figure 5:

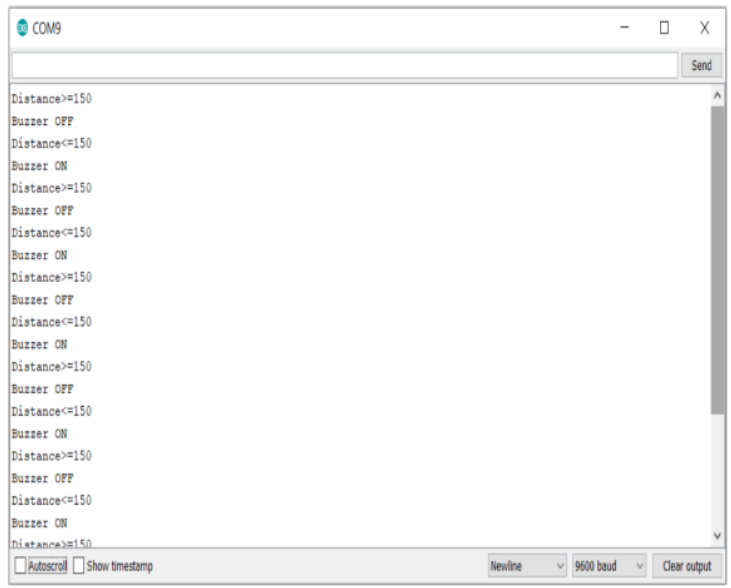

Figure 5: Serial Monitoring of the proposed system

\section{RESULTS}

\begin{tabular}{|l|l|l|}
\hline Humans & Distance $(\mathrm{cm})$ & Buzzer \\
\hline Person 1 & $>=150$ & OFF \\
\hline Person 2 & $<=150$ & ON \\
\hline Person 3 & $>=150$ & OFF \\
\hline Person 4 & $<=150$ & ON \\
\hline Person 5 & $>=150$ & OFF \\
\hline Person 6 & $<=150$ & ON \\
\hline Person 7 & $>=150$ & OFF \\
\hline
\end{tabular}

If the distance is more than $150 \mathrm{~cm}$ the buzzer will remain OFF and if the distance becomes less than $150 \mathrm{~cm}$ the buzzer will be turned ON.

\section{CONCLUSION}

With government taking extreme steps to contain the spread of novel Coronavirus, it is our duty to follow the advice in letter and spirit. Technology can play a crucial role in facilitating social distancing, which is an effective way of preventing COVID 19. The system described in this paper uses the most commonly used components. A simple, but easy to wear device will help the community at large, in fighting against novel coronavirus.

\section{REFERENCES}

1. https://www.who.int.

2. Prasad et.al: " Transmission Electron Microscopy Imaging of SARS-CoV-2”, DOI:10.4103/ijmr.IJMR 57720

3. www.mohfw.gov.in

4. https://components101.com.

5. www.learningaboutelectronics.com

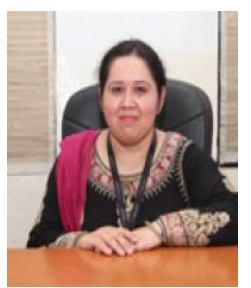

\section{AUTHORS PROFILE}

Dr. Abhiruchi Passi did her B.E in Electronics and Communication Engineering and M.Tech in Electronics and Communication Engineering in 2001 and 2006 respectively. She also did her Masters Diploma in Business Administration from Symbiosis, Pune in 2005. She completed her $\mathbf{P h D}$ in 2016 from Shri Jagadish Prasad Jhabarmal Tibrewala University. She has over $\mathbf{1 7}$ years of teaching experience and presently she is Associate Professor in the Electronics and Communication Engineering Department of Manav Rachna International Institute of Research and Studies, Faridabad, India. She has more than 28 papers published in various National and International Journals and Conferences. Her areas of interest are RF power solutions (Microstrip Filters), Wireless and Data Communication and Internet of Things. She is a member of Institution of Engineers, Life member of ISTE and Member of IAENG.

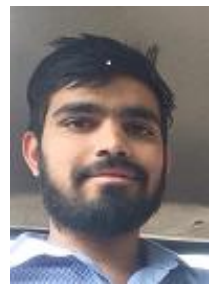

Mr Devdutt completed his B.E in Electronics and Communication Engineering in 2015-2019 from Manav Rachna International Institute of Research and Studies. He is a chip level and card level certified Engineer in computer SMD Electronics by $\mathrm{HI}$ Tech Institute of Advance Technologies (P) Ltd. He is an Intel Higher Education Challenge 2017 winner, Robotic National Champion at IIT Guwahati, Aster Piece Living Talent Dubai 2017 under top 15 teams in the world, Robotics Gold Medalist at IIT Guwahati in 2018, IESA Makeathon 2018 winner, IESA Makeathon South campus golden ticket winner 2018 , Microsoft Imagine Cup National finalist 2018, E- Summit'19 Makeathon 2019 winner at IIT Roorkee, World Arduino Day 2019 winner, Faridabad Industrial Association 2019 winner, Awarded by Renesas GR Lychee Design Contest for India's top 15 innovation idea. Developer circle Chandigarh octal Hackathon by Facebook 2019 winner. He has been honoured by Manav Rachna International Institute of Research and Studies with golden batch for best Innovator. He has 3 filed patents and 4 papers published to his credit. His area of interest includes Robotics and Embedded Systems. His all the achievements and awards are dedicated to his Parents and Mentors. Currently, he is a core member of an USA based IoT solution startup Company.

Published By:

Blue Eyes Intelligence Engineering \& Sciences Publication

(c) Copyright: All rights reserved.

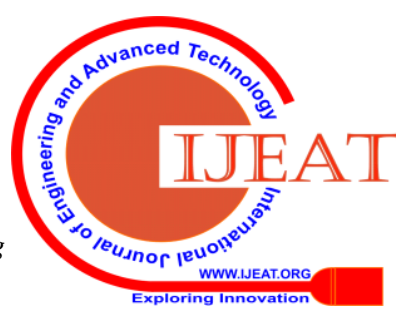

